Article

\title{
Physical Science Teacher Skills in a Conceptual Explanation
}

\section{David Geelan (1)}

School of Education and Professional Studies, Griffith University, Parklands Drive, Southport, QLD 4222, Australia; d.geelan@griffith.edu.au

Received: 9 December 2019; Accepted: 15 January 2020; Published: 17 January 2020

\begin{abstract}
There is a long history of philosophical inquiry into the concept of explanation in science, and this work has some implications for the ways in which science teachers, particularly in the physical sciences (physics and chemistry), explain ideas to students. Recent work has outlined a constructivist approach to developing, delivering, and refining explanations focused on enhancing student's understanding of the powerful concepts of science. This paper reviews the history of concepts of explanation in science and in science teaching, and reports research findings that describe some ways in which science teachers have been observed to explain ideas in Year 11 Physics classrooms in Australia and Canada.
\end{abstract}

Keywords: physics; physical science; science teaching; explanation; explain

\section{Introduction}

Explaining the powerful concepts of science to students is one of the key skills required by teachers of the physical sciences [1]. It draws on knowledge of both science content and student characteristics [2]. Explanation in science teaching has some similarities and some differences compared with explanation in science [3].

Explanations in science-reported in peer reviewed scientific journal articles, for example-are intended to explain the reasons for particular phenomena in the natural world. An explanation in science might explain, for example, why water expands when it freezes, in terms of the structure of the water molecule and the hydrogen bonding that occurs when water moves from the liquid to solid state. Each such element of the explanation is susceptible to further explanation: the shape of the molecule is explained by covalent bonding and valence shell electron pair repulsion theory. It could be argued that there is an almost infinite regress possible, and judgement becomes important in deciding the appropriate level of detail for a particular explanation to a particular audience for a particular purpose.

Explanations in science teaching (sometimes called 'explications of a scientific explanation') [4] are intended to develop understanding on the part of students. A science teaching explanation for the phenomenon of water expanding when it freezes would draw on students' existing understanding, and perhaps also include the use of visualizations such as molecular models. It would draw on students' existing knowledge of the particle model of matter and how powerful it is, and would continue to build their understanding that the observable properties of substances are explained by structures and interactions at the atomic level.

This paper has two main aims:

1. To introduce readers to the historical background and theoretical approach taken to the study of science teaching explanations; and

2. To report the results of an empirical study conducted in Australian and Canadian Year 11 physics classrooms. 
The paper briefly discusses the philosophical discussion of explanation in science and considers its implications for explanation in physical science teaching, then reports empirical research conducted in Australia and Canada into physics explanations in classrooms, including a description of the common features identified in such explanations.

Much of the research base on science teaching explanations, including the work of Treagust and Harrison [3] and Sevian and Gonsalves [2], draws on explanations given by scientists when they are teaching university classes, but the literature contains few examples of the features of explanations given in secondary school classrooms. The research reported in this paper is intended to contribute to knowledge of such explanations in order to complement the features identified by Treagust and Harrison [3].

\section{Background}

\subsection{Explanation in Science}

Natural philosophers back to Plato and Aristotle have considered the question of what it is to 'explain' natural phenomena. David-Hillel Ruben, in his book Explaining Explanation, offers a valuable overview [5].

Perhaps the most influential work in the philosophy of explanation is the 1948 paper by Carl Hempel and Paul Oppenheim, Studies in the Logic of Explanation [6]. It advances a 'deductive-nomological' account of explanation, in which an explanation of a scientific phenomenon consists of a set of sentences outlining initial conditions, combined with a scientific law or laws. The expansion of a sample of gas when heated might be explained, for example, by a set of initial conditions of temperature and pressure combined with Charles' Law.

Hempel [7], in response to the existence of probabilistic (rather than deterministic) natural phenomena such as radioactive decay, later added an 'inductive-statistical' model, which applies to outcomes that are highly probable but not certain given the correct initial conditions and the application of the appropriate scientific law.

Wesley Salmon [8] noted that there are phenomena for which we would ascribe causation for which the probability is nonetheless low. He uses the example of smoking, where the incidence of lung cancer among lifelong smokers is on the order of 0.2 , but we would still consider that the smoking caused the cancer. Salmon initially proposed a 'statistical-relevance' model that focused attention on the specific features of a situation that were causally relevant, but later replaced this model with a 'causal-mechanistic' approach.

While the approaches of Hempel and Salmon focus on an explanation as one or other form of written artifact that can be abstracted from the context in which it is given, Paul Achinstein [9] focused on the giving of explanations-of explanation as a verb rather than a noun. He identifies explaining as a speech act, of a kind he describes as 'illocutionary'. In this account, characteristics of both the person giving the explanation (the explainer) and the person receiving it (the explainee) are relevant to judging the quality of the explanation and its appropriateness for purpose. It is possible to use the same words for the purpose of explaining something (a doctor saying 'Bill ate spoiled meat' to explain Bill's stomach ache) and for the purpose of criticizing someone (Bill's wife saying 'Bill ate spoiled meat' to criticize Bill's culinary choices). Taking the text in isolation would not make it possible to know whether this text was an explanation or not.

Achinstein proposes the following criteria for the 'good-ness' of an explanation:

(a) The audience does not already understand it

(b) There is a way to explain it that will allow the audience to know the correct answer and that it is a correct answer

(c) The audience is interested in the explanation

(d) It will be valuable for the audience to understand the explanation. 
This approach is more closely relevant to science teaching explanations than those of Hempel and Salmon because it centrally includes the explainer and the audience. The key challenges of delivering explanations in teaching lie in ensuring that conditions (c) and (d) above are met-that our students are interested in the explanations we offer, and that the explanations we offer will be valuable for our students. This last is not the same thing as 'the audience knows that it will be valuable to understand'. That would be ideal but is not essential, as long as the explainer knows it. The explanations we give in science teaching should transform worldviews and offer tangible benefits to students.

\subsection{Explanation in Science Teaching}

Achinstein's approach brings us to the phenomenon of interest in this paper, which is the giving of conceptual explanations to students in science classrooms. This is a different kind of activity to the creation of scientific explanations, and is sometimes called 'the explication of an explanation' [4]. That is, the scientific theory explains the phenomenon and the teacher offers an explication (a making explicit) of this explanation to the student. Rather than 'explication' the term 'science teaching explanation', borrowed from David Treagust and Allan Harrison [3], has been adopted in this paper for what teachers do, as distinct from the 'science explanation' that is a key activity of science.

Treagust and Harrison [10] draw on Ruben's [5] work to discuss issues around explanatory frameworks:

There are important philosophical and epistemological differences between science explanations and science teaching explanations. Science explanations are strictly characterized as theory and evidence-driven, use the correct scientific terms and include analogical models. Science teaching explanations differ in rigor, length and detail, involve varying degrees of 'explain how' and 'explain why', are sometimes open-ended, include human agency and can raise new questions as they answer previous questions. (p. 1158)

Treagust and Harrison [10] discuss Richard Feynman's [11] lecture 'Atoms in motion' as an exemplar of excellent explanations in physics teaching. Context is very important in assessing the quality of explanations, particularly those given with a pedagogical intent: to give a trivial example, an explanation of physical quantities and processes that is appropriate for an 8 year old would not be appropriate in a 3rd year university physics course, but it might be the perfect explanation right now.

Explanations given by teachers to students can be anthropomorphic, teleological, and use analogies and metaphors.

Treagust and Harrison identified these features in their analysis of Feynman's lecture:

- analogies and metaphors, including anthropomorphisms and teleological explanations;

- careful qualification of analogies and attention to places in which the analogies break down or no longer usefully map onto the target concept;

- use of axioms of physics, accompanied by explicit attention to the evidence from experience and experiment that supports those axioms;

- development of physics concepts and their elucidation through carefully chosen examples;

- dynamic use of both imagination and reason (logic) in explanation; and

- development within the listener of a 'dynamic and fluid mental model'.

Like the work of Sevian and Gonsalves [2], Treagust and Harrison's [3] discussion takes the science teaching explanations provided by scientists who are explaining scientific concepts, usually to university student audiences, as a kind of 'gold standard' for the quality and features of science teaching explanations. The present project seeks to complement this work and contribute to knowledge in science education by reporting on the ways in which secondary school physics teachers in Australia and Canada explained physics concepts to their students.

Explanation might be thought of as a 'transmissive' activity in which a teacher stands at the front of the classroom and delivers a lecture, perhaps reading it from notes used over many years, to the 
class members who passively receive it. This is far from the case in most real science classrooms, of course. Explaining is an interactive process in which teachers work with and receive feedback from their students 'in the moment' about how the explanation is being received, and check for student engagement and comprehension. They also construct their explanations in the context of the knowledge which they have developed across the current school year, or even multiple years, of their students' knowledge, interests, needs, and characteristics.

Christoph Kulgemeyer and Josef Riese [12] have described a constructivist approach to explanation in science teaching, drawing on work from Merten [13] and Rusch [14]. Within this framework, the 'explanation' is an artifact that exists in some sense in itself, but the process of 'explaining' consists of providing experiences and 'materials', with which students construct their own understanding of the target concept. The explanation may be delivered once, then adapted, augmented, and revised to meet the student's needs and the feedback received. These authors, with other colleagues in Germany, have published a considerable body of research around assessing the quality of the explanations offered by beginning and experienced teachers, and some of this work is discussed below.

If an explanation is given in a context in which direct feedback from the explainee(s) is not available, such as in a textbook chapter, instructional video or similar context, then the explainer must in some sense have a mental model of the explainee-some set of assumptions about their interests, existing knowledge, purposes, and other characteristics. The explanation will be designed to be as good as possible for enhancing understanding on the part of this imagined audience, but to the extent that this mental model does not match the audience, the explanation may be less effective than it would be with a better match. This may be a reason to prefer and champion 'live' face-to-face explanations where explainer and explainee are in the same room over 'flipped classroom' teaching approaches where explanations are given on video without live feedback, or over attempts on the part of students to learn physics from YouTube videos, MOOCs (Massive Open Online Courses), or textbooks alone.

\subsection{Evaluating the Quality of Explanations in Science Teaching}

A number of researchers have considered the issue of how the quality of explanations in science education can be evaluated. Hannah Sevian and Lisa Gonsalves [2] created a rubric for judging the quality of science teaching explanations. It draws on Lee Shulman's [15] distinction between content knowledge, pedagogical knowledge, and pedagogical content knowledge, and offers evaluations of explanations. Their approach was applied to explanations by scientists, considered as single, isolated artifacts. As such, this approach has value, but does not explicitly address the 'explaining' element - the active and interactive work that teachers do with students to adapt and improve their explanations to enhance understanding.

Jörg Wittwer and Alexander Renk1 [16] considered why instructional explanations often do not work as intended, and offered a framework for judging the quality of explanations. Like that of Sevian and Gonsalves, this framework focuses on the explanation rather than on the process of explaining. They suggest that instructional explanations should:

- be adapted to the learner's knowledge prerequisites

- focus on concepts and principles

- be integrated into the learner's ongoing cognitive activities

- not replace learner's knowledge-construction activities.

Brigandt [17] developed a concept of 'explanatory aims' that he suggests allows explanation and explaining to be assessed in a more nuanced way that is more appropriate to the actual reasons for which a particular explanation is being given, in a particular context and for a particular audience. He notes:

What makes it additionally important to be clear about the standards used to adjudicate what counts as a good explanation is the fact that such standards can differ across explanations. 
While some accounts have to point to laws of nature in order to be explanatory, others can do without reference to laws, and instead explain why something happens in terms of describing how it is brought about by a mechanism. This suggests that different standards of explanatory adequacy correspond to different types of explanations, as used in different fields of science, for example, law-based explanations in physics as opposed to mechanistic explanations in molecular biology. (p. 258)

Kulgemeyer and a number of colleagues in Germany have published a series of papers that focus on teacher's 'action-related competencies', their ability to explain to particular students in particular contexts [18-20]. Different facets of the research use students trained as actors to respond in particular ways and ask particular questions, or use video vignettes to play a similar role, and then ask beginning teachers to select the best 'next move' in the explanation and to give their reasons for their decision. This is exciting work with considerable potential to enhance the understanding, teaching, and assessment of beginning teachers' skills in explaining science concepts to students. Their work is conducted in a more 'laboratory-like' context as they seek to create and validate robust assessments of teacher skills.

While some research has been published that reports on the ways in which teachers explain science concepts to students [21] the literature is still relatively 'thin', and the present project was designed to contribute to that literature. It does not so much fill a 'gap' in knowledge but rather seeks to 'thicken' the description of the ways in which explanations are delivered in classrooms.

\section{Classroom Explanation in Australian and Canadian Physics Classrooms}

In order to contribute to the development of a richer naturalistic picture of the ways in which teachers explain physics concepts to students, $2-4 \mathrm{~h}$ of video was recorded in each of sixteen (16) Year 11 (students aged 14-17) Physics classrooms (four (4) in Perth, Australia and twelve (12) in Edmonton, Canada). Participants in each city freely gave written consent to participate and were informed that they could withdraw from the study, and have any data collected from them destroyed, without penalty. The study was approved by the Research Ethics Boards of Edith Cowan University (Perth) and the University of Alberta (Edmonton). Students who did not consent to be video recorded were placed at the sides of the classroom where they were invisible to the camera.

\subsection{Materials and Methods}

The Australian schools were chosen on the base of a 'value-added' measure, which used a correlation between student's physics scores and their scores on a generalized test of academic ability. During a 10-year period all students completing the Western Australian Tertiary Entrance Examinations (TEE) also completed a Scaling Test, which was a general test of academic aptitude. A regression line that compared examination results with academic aptitude scores and socioeconomic status was constructed. The regression line identified the 'expected achievement' level for a school in a suburb with a particular socioeconomic status. (The fact that wealth predicts academic achievement is problematic but is beyond the scope of the present paper.) Schools in which the aggregate of student physics scores was more than 1 standard deviation higher than would be expected based on their general aptitude and socioeconomic status were identified as 'successful schools'. Schools were chosen in suburbs with a range of socioeconomic statuses.

This method of selecting schools and teachers was not possible when selecting the Canadian schools, because no such general test of ability was conducted. In this case 'successful' teachers were identified to join the study based on recommendations-which identified the teachers as particularly skilled and effective physics teachers-from colleagues and school leaders and in a 'snowball sampling' method where teachers already invited to participate suggested the names of colleagues in other schools who they held in high esteem.

In addition to the video recordings, teachers participated in semi-structured interviews after the observed lessons, and focus groups of $4-5$ students were also interviewed in a semi-structured 
way. Questions, in both cases, focused on features of the lesson just observed, on the things students liked about their teacher's teaching and approach, on students and teacher's perceptions about the features of good explanations and the things that fostered student understanding. Teachers were asked about characteristics of the specific student cohort observed and characteristics of the school and community more broadly. Students were asked about their motivation for studying physics. Where demonstrations or experiments were included these were discussed, and issues like the use of technologies such as data projectors occurred in an ad hoc way if it was observed in lessons. While there was a point-form overview of areas to address in the interviews and focus groups, the approach was to conduct a naturalistic professional conversation about teaching and professional judgements with the teachers, and to allow students to discuss the things that were important to them about their learning.

\subsection{Results}

The culture in the physics classrooms in these two countries was so similar that international comparisons revealed little, and the data were coded as a single large set.

In the interviews, in general, teachers described characteristics of their students, the community they came from, their aspirations and struggles and the ways in which the teacher sought to modify the explanations to enhance student understanding and address common misconceptions. All of the participating teachers subscribed to a constructivist view of learning and a Popperian view of the nature of science, and described their physics teaching in terms of inquiry models, however the observed teaching tended to be quite teacher-centered and teacher-led. This is perhaps unsurprising, however, since the video camera was turned on for teacher explanations and off for small groups discussions, experiments, 'desk work' (students working independently on calculations or problems) and other learning activities because of the focus of the study. Across a whole course the balance between student- and teacher-led learning activities would have been different. Students sometimes said that they were studying physics because they were interested in it, but much more often the reasons were either instrumental-in order to gain access to university degrees they wished to pursue or because physics was perceived to be a subject that would yield higher university entrance scores-or because their parents had encouraged them to do so. Some had also been strongly encouraged by teachers to study physics, based on their performance in junior secondary science.

Students were generally very positive about the teaching of their teachers and felt that they were well-served in terms of seeking to understand the key concepts of physics. Those who reported struggling in their studies often talked more about difficulties with mathematics than with the concepts of physics.

Students overwhelmingly identified two key things that they valued and respected in their teachers: "They know their stuff" - their content knowledge in physics is strong and reliable and "They know me"- students were engaged to the extent that teachers actively engaged with them and came to know them as fully-rounded people. This knowledge of students on the part of teachers is a crucial part of what informs the in-the-moment process of developing and modifying explanations in the classroom.

While there were differences in the ways in which particular physics concepts were explained by different physics teachers, and some explanations were clearer and more transparent than others, none of the explanations given were factually incorrect in terms of the physics content knowledge being communicated. This may have been an artifact of the ways in which teachers were selected to participate in the study.

Common features of the ways in which teachers explained physics concepts were coded on the video recordings, using the open-source video coding package Transana. The dimensions of the coding were grounded in the existing research work in the field by Treagust and Harrison [3] and in the researcher's own experience as a physics teacher, but were complemented and augmented by the development of new categories for emergent phenomena that had not been anticipated. The importance of humor and rapport, for example, was a phenomenon not included in Treagust and Harrison's work 
or anticipated in developing the initial coding scheme, but arose from observation during the lessons and repeated watching of the videos, as well as from the teacher interviews and student focus groups. On one hand it could be argued that the video vignettes were coded until saturation, but on the other it could be argued that it would be possible to return to the same video vignettes in future when attention has been drawn to an additional facet of science teaching explanations in classrooms (for example by the research of others) and to re-code the video in relation to this new facet. This is one of the affordances of video over text (even the text of transcriptions of video): it is so rich that it is difficult to genuinely exhaust it.

Coded features were as follows:

- The use of analogies and metaphors, with a separate code where teachers paid explicit attention to the ways in which the analogical concept was unlike the target concept (i.e., the places where the analogy breaks down)

- Instances where teachers worked through calculations on the whiteboard or smartboard

- Use of diagrams and of electronic animations or simulations

- Use of apparatus and demonstrations in explanations

- Use of anthropomorphic and teleological language

- Teacher's use of hand gestures or body movements to illustrate their explanations

- Appeals to earlier learning in the course

- Drawing on knowledge from other courses the students are taking (usually, but not always, mathematics)

- Explicit allusions to assessment such as "you'll need to know this for the test" or "this is how I would do this problem in an exam"

- Use of questions including open- and closed-ended questioning

- Jokes and humor, including pop-culture allusions.

Because the sampling was conducted in an ad hoc manner in response to the demands of the schools in question, at different times of the school year (and around the demands of a full-time academic teaching load for the researcher), different amounts of video were recorded in different classrooms, and the activities in which students were engaged involved different levels and kinds of teacher explanations. As such, a tally table of frequencies of the particular codes would not be meaningful, since there was not sufficient uniformity in the contexts in which the video data were recorded.

Coding was completed by the researcher, with peer debriefing of a sample by a colleague at the University of Alberta. It would have been ideal to have the video independently coded by more than one researcher, however the project was not funded in a way that would have allowed that level of investment. The researcher watched and coded each segment multiple times and explicit sought discrepant cases and disconfirming evidence [22].

There were patterns to the kinds of explanations used to explain particular topics (Table 1). Motion (distance, acceleration, speed and velocity) is quite directly linked to student's everyday experience, whereas the flow of electric current is observed more indirectly as a globe lighting up or a movement of the reading on a meter. This meant that analogies were used more often for electricity than for motion, including the fact that teachers often used analogies from motion (e.g., water flowing in a hose) to explain concepts in electricity. 
Table 1. Features of science teaching explanations related to specific physics topics.

\begin{tabular}{|c|c|}
\hline Topic & Features of Explanations \\
\hline Kinematics-simple motion & $\begin{array}{l}\text { Demonstrations with objects such as dynamics trolleys in } \\
\text { the classroom } \\
\text { Student experience of sport or vehicles, existing conceptions } \\
\text { about motion } \\
\text { Challenge to impulse views of motion }\end{array}$ \\
\hline Dynamics - motion, force and energy & $\begin{array}{l}\text { Appeal to the idea of how much work it takes to achieve a } \\
\text { particular resultUse of the idea of "power" as related to cars } \\
\text { and motorcycles }\end{array}$ \\
\hline Electricity—static, current, simple circuits & $\begin{array}{l}\text { Very frequent analogies between electric current and water } \\
\text { currentCircuit diagrams and attention to conventions of } \\
\text { drawing and analyzing circuit diagrams }\end{array}$ \\
\hline Gravitation & $\begin{array}{l}\text { Student's imagination of being in space } \\
\text { Reference to science fiction movies } \\
\text { Links to circular motion } \\
\text { History of science and the geocentric/heliocentric } \\
\text { controversy }\end{array}$ \\
\hline Circular and simple harmonic motion & $\begin{array}{l}\text { Demonstrations-swinging and spinning objects } \\
\text { Analogies between circular motion and SHM } \\
\text { Links to planetary orbits and gravitation }\end{array}$ \\
\hline Light-nature, reflection, refraction & $\begin{array}{l}\text { Demonstrations using laser pointers Analogies between: } \\
\text { (1) particle nature of light and objects such as balls, (2) wave } \\
\text { nature of light and water waves }\end{array}$ \\
\hline
\end{tabular}

A common feature in many of the observed explanations was the "move to mathematics"-teachers often began explanations of phenomena in a qualitative mode, perhaps with a demonstration or by asking the students to imagine a hypothetical physical situation, but most moved quite quickly to formalize the qualitative information with symbols, units, equations, and calculations.

Storytelling and references to the history of science were also frequent features of explanations. Stories such as Rutherford's explanation that he was as surprised when the alpha particle bounced back from the gold foil as he would have been if a cannonball had bounced off a sheet of tissue paper, as well as Archimedes' (probably apocryphal) bath and Newton's (likewise) apple added human interest and connection to the concepts being learned.

Various information and communication technologies (ICTs), from chalk on a chalkboard to ticker-timers, have always been part of explanations in physics teaching, but the use of several newer technologies was notable in the classrooms studied. Measurement probes such as light gates and timers, laser pointers and the use of slow-motion video on smartphones were elements of instruction, as was the combination of data projectors with whiteboards to allow images to be annotated.

Different teachers had different personal styles, and physics teacher humor tends to be quite dry, but many of the teachers used humor with their students to help build relationships and improve the classroom climate. Building rapport was recognized as a key part of enhancing student understanding.

These features were common to many or most of the science teaching explanations observed in the study, and seemed to be relatively robust features of explanations in secondary school Physics classrooms. The question of to what extent and in what ways these features might be shared with teaching explanations in Chemistry, Biology, Earth Science, Environmental Science, and other science disciplines is one in need of further research. Kostas Kampourakis and Vasso Zogza [23] and Brigandt $[17,24]$ are writing very interesting work around explanation of evolution and other concepts in biology. 


\section{Discussion}

The following features of science teaching explanations were identified in the Australian and Canadian Year 11 physics classrooms in which lessons were video recorded:

1. The 'move to mathematics'

2. Attention to the requirements of success on external exams

3. Use of analogies

4. Storytelling and references to the history of science

5. Role of technology

6. Humor.

This list shares some similarities and differences with the list proposed by Treagust and Harrison [3] based on a lecture by Feynman [11]. Their list is as follows:

- analogies and metaphors, including anthropomorphisms and teleological explanations;

- careful qualification of analogies and attention to places in which the analogies break down or no longer usefully map onto the target concept;

- use of axioms of physics, accompanied by explicit attention to the evidence from experience and experiment that supports those axioms;

- development of physics concepts and their elucidation through carefully chosen examples;

- dynamic use of both imagination and reason (logic) in explanation; and

- development within the listener of a 'dynamic and fluid mental model'.

Elements such as the use of analogies are common. It could be argued that some of the other elements identified in the present study also involve the use of both imagination and reason, and that most or all of them are directed toward the goal of creating a dynamic and fluid mental model in the mind of the learner of the physical phenomena being studied.

There are some elements that were common to most or all teachers in the study, and the similarities between physics classrooms across two countries and a range of suburbs of different socioeconomic status were striking. There were also noticeable differences. Some teachers tended to direct their questions to the few students at the front of the room who they knew would provide the correct factual answer to their questions and then move on. Teachers in this group tended to ask "Does anyone have any questions?" after offering an explanation, but not allow any "wait time" for students to respond. Others conducted extended, almost Socratic, dialogues with the whole class, drawing out student's understandings, and challenging misconceptions. Teachers in this latter group would often question the same student multiple times, and would intentionally distribute questions to a wide range of students within the class rather than focusing on a few.

There are common features in the explanations offered by successful physics teachers, but there is also a huge range of contextual features related to the students, the teacher, the school, the community, the syllabus, and a wide variety of other influences that moderates these explanations when they are given in particular instances. These individual differences underlined the notion that "best practice" or "exemplary practice" is a slippery concept. What constitutes the best explanation for one student or class in context may be quite unhelpful to a student in a different context.

These were all teachers who had been identified as 'successful', and were all delivering scientifically correct explanations. While there are definitely ways to be a 'bad' physics teacher, for example by delivering scientifically incorrect explanations or through apathy and carelessness for student learning, there were all 'good' physics teachers despite-or perhaps because of-their differences. There are many ways to be a good physics teacher, and learning from the explanatory skills and practices of others is one way to continue the on-going professional growth that best serves students' learning. 


\section{Conclusions}

There remains considerable research work still to be done around explanations in science teaching, in particular around the extension of modes from physics and physical science education to biology education and other science disciplines, as well as into how to support a teacher's development of the explaining skills. Sevian and Gonsalve's [2] scheme has not yet been applied to explanations given by secondary school physics teachers in classrooms, and has potential to further build knowledge around the features and quality of teaching explanations.

The ability to construct, adapt to student needs and interests, deliver, receive feedback on, adapt, and re-deliver science teaching explanations is an important skill for teachers in physics and chemistry. Such explanations draw on teacher's science content knowledge, but also on their knowledge of their students, and their rapport and relationships with them.

The present study identified several features of the ways in which teachers explain concepts to students, as a contribution to understanding the features of explanations. With complementary work being conducted by Kulgemeyer and colleagues [18], it has the potential to inform the ways in which teachers develop their skills both in their pre-service teacher education and through professional development opportunities and experience.

Funding: This research project received no external funding.

Conflicts of Interest: The author declares no conflict of interest.

\section{References}

1. Schneider, R.M.; Plasman, K. Science Teacher Learning Progressions: A Review of Science Teachers' Pedagogical Content Knowledge Development. Rev. Educ. Res. 2011, 81, 530-565. [CrossRef]

2. Sevian, H.; Gonsalves, L. Analyzing how scientists explain their research: A rubric for measuring the effectiveness of scientific explanations. Int. J. Sci. Educ. 2008, 30, 1441-1467. [CrossRef]

3. Treagust, D.; Harrison, A. The genesis of effective scientific explanations for the classroom. In Researching Teaching: Methodologies and Practices for Understanding Pedagogy; Loughran, J., Ed.; Falmer Press: London, UK, 1999; pp. 28-43.

4. Carnap, R. Logical Foundations of Probability; University of Chicago Press: Chicago, IL, USA, 1950.

5. Ruben, D.H. Explaining Explanation, 2nd ed.; Paradigm: London, UK, 2012.

6. Hempel, C.; Oppenheim, P. Studies in the Logic of Explanation. Philos. Sci. 1948, 15, 135-175. [CrossRef]

7. Hempel, C. Aspects of Scientific Explanation, and Other Essays in the Philosophy of Science; The Free Press: New York, NY, USA, 1965.

8. Salmon, W. Four Decades of Scientific Explanation; University of Pittsburgh Press: Pittsburgh, PA, USA, 2006.

9. Achinstein, P. The Nature of Explanation; Oxford University Press: New York, NY, USA, 1983.

10. Treagust, D.; Harrison, A. In search of explanatory frameworks: An analysis of Richard Feynman's lecture 'Atoms in motion'. Int. J. Sci. Educ. 2000, 22, 1157-1170. [CrossRef]

11. Feynman, R. Six Easy Pieces; Basic Books: New York, NY, USA, 1994.

12. Kulgemeyer, C.; Riese, J. From professional knowledge to professional performance: The impact of $C K$ and PCK on teaching quality in explaining situations. J. Res. Sci. Teach. 2018, 55, 1393-1418. [CrossRef]

13. Merten, K. Konstruktivismus als Theorie für die Kommunikationswissenschaft. MedienJournal 1995, 4, 3-21.

14. Rusch, G. Eine Kommunikationstheorie für kognitive Systeme. In Konstruktivismus in der Medien-Und Kommunikationswissenschaft; Rusch, G., Schmidt, S., Eds.; Suhrkamp: Frankfurt, Germany, 1999; pp. 150-184.

15. Shulman, L. Those who understand: Knowledge growth in teaching. Educ. Res. 1986, 15, 4-14. [CrossRef]

16. Wittwer, J.; Renkl, A. Why instructional explanations often do not work: A framework for understanding the effectiveness of instructional explanations. Educ. Psychol. 2008, 43, 49-64. [CrossRef]

17. Brigandt, I. Explanation in biology: Reduction, pluralism, and explanatory aims. Sci. Educ. 2013, 22, 69-91. [CrossRef]

18. Bartels, H.; Geelan, D.; Kulgemeyer, C. Developing an approach to the performance-oriented testing of science teachers' action-related competencies. Int. J. Sci. Educ. 2019, 41, 2024-2048. [CrossRef] 
19. Kulgemeyer, C.; Schecker, H. Physikalische Kommunikationskompetenz - Empirische Validierung eines normativen Modells [Empirical validation of a normative model for communicating physics]. Zeitschrift für Didaktik der Naturwissenschaften 2012, 18, 29-54.

20. Kulgemeyer, C.; Schecker, H. Kommunikationskompetenz in der Physik: Zur Entwicklung eines domänenspezifischen Kompetenzbegriffs [Developing a domain-specific communication model for physics]. Zeitschrift für Didaktik der Naturwissenschaften 2009, 15, 131-153.

21. Geelan, D. Teacher explanations. In Second International Handbook of Science Education; Springer: Dordrecht, The Netherlands, 2012; pp. 987-999.

22. Booth, A.; Carroll, C.; Ilott, I.; Low, L.L.; Cooper, K. Desperately seeking dissonance: identifying the disconfirming case in qualitative evidence synthesis. Qual. Health Res. 2013, 23, 126-141. [CrossRef]

23. Kampourakis, K.; Zogza, V. Preliminary evolutionary explanations: A basic framework for conceptual change and explanatory coherence in evolution. Sci. Educ. 2009, 18, 1313-1340. [CrossRef]

24. Brigandt, I. Beyond reduction and pluralism: Toward an epistemology of explanatory integration in biology. Erkenntnis 2010, 73, 295-311. [CrossRef]

(C) 2020 by the author. Licensee MDPI, Basel, Switzerland. This article is an open access article distributed under the terms and conditions of the Creative Commons Attribution (CC BY) license (http://creativecommons.org/licenses/by/4.0/). 